Identification of dihydrogambogic acid as a matrix metalloproteinase I inhibitor by high-throughput screening

This article was published in the following Dove Press journal: Clinical, Cosmetic and Investigational Dermatology

\section{Yong $\mathrm{Li}$ \\ John J Voorhees \\ Gary J Fisher}

Department of Dermatology, University of Michigan, Ann Arbor, MI, USA
Correspondence: Gary J Fisher Department of Dermatology, University of Michigan, Ann Arbor, MI, USA Tel +l 734763 I469

Email gjisher@med.umich.edu

\section{Introduction}

Type I collagen (COL1) is the predominant structural protein in the skin. COL1 forms densely packed fibrils which are essential for maintaining skin mechanical properties and youthful appearance. ${ }^{1}$ The enzyme matrix metalloproteinase-1 (MMP1) cleaves COL1 fibrils at a single site. ${ }^{2}$ Once cleaved by MMP1, COL1 fibrils can be degraded by other proteases. MMP1 expression is elevated during natural aging and chronic sun exposure, ie, photoaging, leading to excessive degradation of COL1. ${ }^{3}$ This excessive degradation contributes to COL1 deficiency in the skin of the elderly. COL1 deficiency impairs skin structural integrity and appearance.

Given the detrimental role of MMP1 in mediating age-associated fragmentation of COL1 fibrils, it would be beneficial to include MMP1 inhibitors in topical antiaging skin care products. Naturally existing substances that are safe for human use, such as botanical extracts, are often used in skin care products. We have utilized highthroughput screening (HTS) to identify naturally existing MMP1 inhibitors that could be used for cosmetic purposes.

\section{Methods}

We adapted the MMP1 activity assay from a previous HTS study, which was designed for identifying MMP inhibitors. ${ }^{4}$ This assay utilized recombinant MMP1 catalytic domain (MMP1-CD) to cleave a fluorogenic peptide containing the COL1 cleavage sequence. ${ }^{5}$ Upon cleavage by MMP1, the peptide substrate emits fluorescence. The magnitude of fluorescence is a measure of MMP1 activity. ${ }^{4}$ We investigated the kinetics of peptide cleavage by MMP1-CD (Figures S1 and S2) and determined optimal assay conditions for HTS. These optimal assay conditions were incubation of MMP1-CD $(0.2 \mathrm{ng} / \mathrm{mL})$ with peptide substrate $(10 \mu \mathrm{M})$ at room temperature $\left(22^{\circ} \mathrm{C}-25^{\circ} \mathrm{C}\right)$ for 3 hours.

We applied these conditions to screen 2,000 compounds (the Bioactive-2000 library purchased from MicroSource Discovery Inc., New Milford, CT, USA), which included both natural and synthetic compounds. Test compounds $(15 \mu \mathrm{M})$ were loaded into 384-well plates using a programmable robotic liquid handling instrument. The results are displayed in Figure 1. Reactions containing the synthetic MMP1 inhibitor, GM6001, were positive controls (red squares in Figure 1) for MMP1 inhibition. These reactions displayed low fluorescence due to inhibition 
of peptide cleavage by GM6001. Reactions that did not contain test compounds or GM6001 were negative reaction controls (purple squares).

\section{Results}

Some test reactions (green squares) displayed fluorescence higher than negative controls, indicating that these compounds may have auto-fluorescence or enhance peptide cleavage. Other test reactions displayed fluorescence lower than negative controls, indicating that these compounds may quench fluorescence or strongly inhibit MMP1 activity.
Among the potential MMP1 inhibitors identified by the HTS, we focused on two compounds celastrol and dihydrogambogic acid (DGA) because they are known to be safe for human use. Celastrol is an active ingredient found in the plant Tripterygium wilfordii, also called Thunder God Vine, which is used in traditional herbal medicine. ${ }^{6}$ DGA is extracted from a medicinal plant, Garcinia hanburyi. G. hanburyi extracts have been used topically to treat inflammatory skin disorders in China. ${ }^{7}$ We further examined the effect of DGA and celastrol on cleavage of native COL1 fibrils by using purified full length activated human MMP1. Celastrol displayed little inhibition on COL1 cleavage

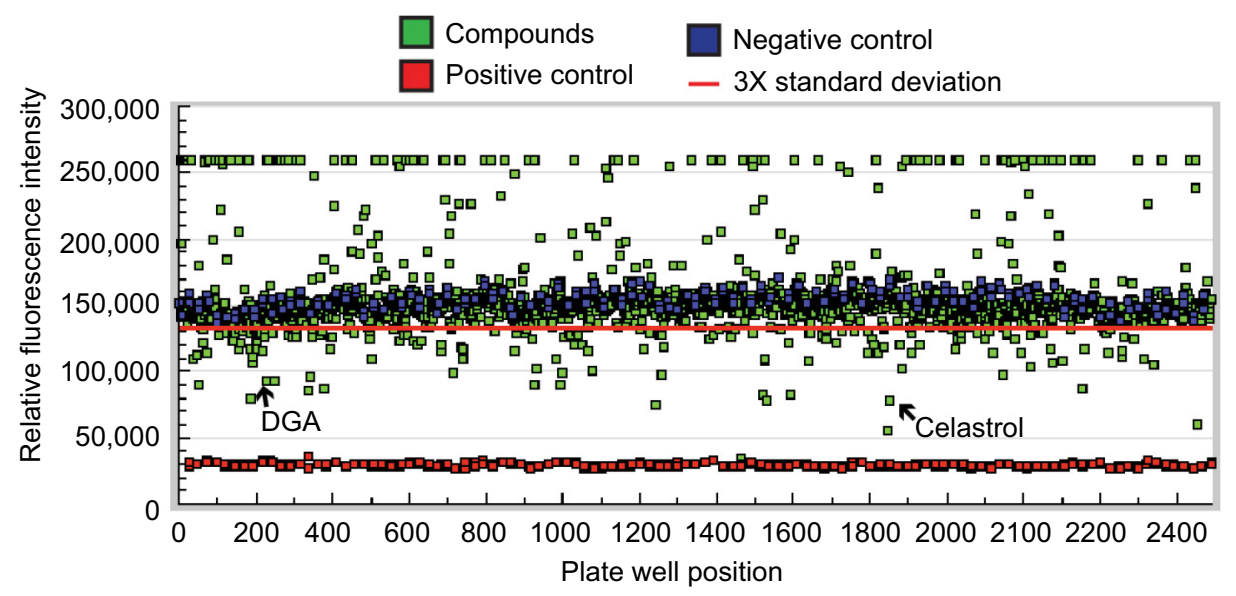

Figure I HTS screening of compounds with MMPI inhibitory activity.

Notes: Scatter plot shows relative fluorescence intensity of individual reactions, which are shown as squares.

Abbreviations: DGA, dihydrogambogic acid; HTS, high-throughput screening; MMPI, matrix metalloproteinase-I.

A

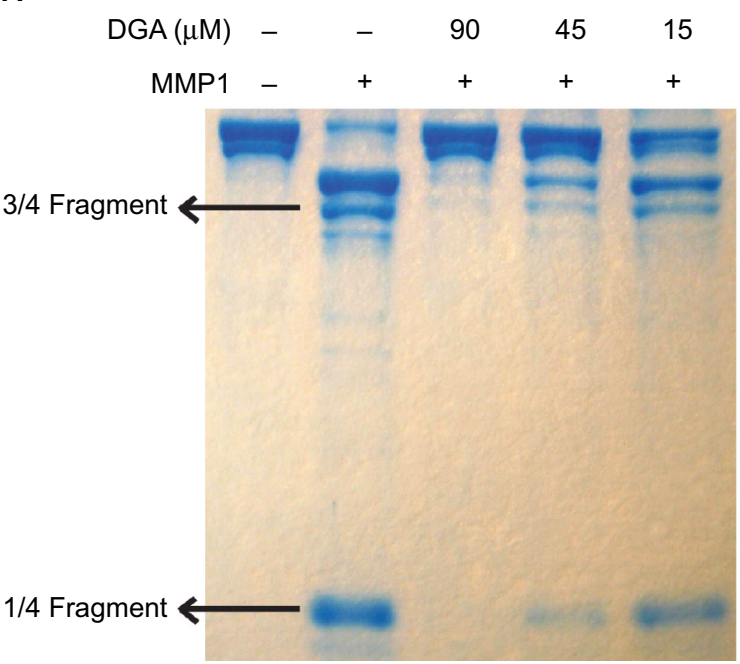

B

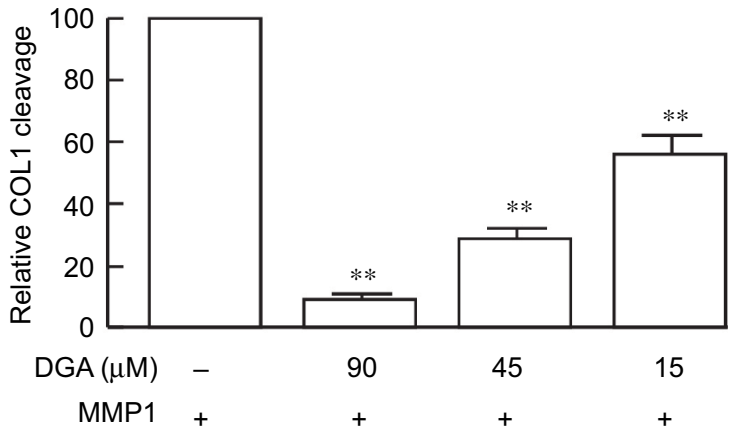

Figure 2 DGA inhibits cleavage of COLI fibrils by MMPI.

Notes: (A,B) MMPI was preincubated with vehicle or DGA for 30 minutes and then added to native COLI. After I6 hours, COLI was dissolved in Laemmi loading buffer. Intact COLI and COLI fragments were separated by SDS-PAGE and visualized by Coomassie blue staining. MMPI cleaved COLI and yielded characteristic fragments with size of "I/4" or " $3 / 4$ " that of intact collagen. Collagen fragments were quantified using ImageQuant software. Results are mean \pm SEM ( $N=3$; $* * 0<0.0$ ). (A) shows a representative gel.

Abbreviations: COLI, collagen I; DGA, dihydrogambogic acid; MMPI, matrix metalloproteinase-I; SDS-PAGE, sodium dodecyl sulfate-polyacrylamide gel electrophoresis; SEM, standard error of the mean. 
(data not shown). In contrast, 15,45 , and $90 \mu \mathrm{M}$ DGA inhibited COL1 cleavage by $44 \%, 71 \%$, and $91 \%$, respectively (Figure 2 ).

\section{Discussion}

The above results indicate that DGA inhibits cleavage of COL1 by human MMP1. This finding warrants future investigations into the efficacy of topical DGA in reducing elevated MMP1 activity in the skin of experimental animals or humans. In addition, our finding demonstrates the utility of HTS to identify compounds of potential benefit to reduce COL1 cleaving in aged human skin.

\section{Acknowledgment}

We thank Diane Fiolek for her help with graphics.

\section{Disclosure}

The authors report no conflicts of interest in this work.

\section{References}

1. Rittie L, Fisher G. Natural and sun-induced aging of human skin. Cold Spring Harb Perspect Med. 2015;5(1):a105370.

2. Li Y, Xia W, Liu Y, Remmer HA, Voorhees J, Fisher GJ. Solar ultraviolet irradiation induces decorin degradation in human skin likely via neutrophil elastase. PLoS One. 2013;8(8):e72563.

3. Quan T, Qin Z, Xia W, Shao Y, Voorhees JJ, Fisher GJ. Matrix-degrading metalloproteinases in photoaging. J Investig Dermatol Symp Proc. 2009;14(1):20-24.

4. Peppard J, Pham Q, Clark A, et al. Development of an assay suitable for high-throughput screening to measure matrix metalloprotease activity. Assay Drug Dev Technol. 2003;1(3):425-433.

5. Bickett DM, Green MD, Berman J, et al. A high throughput fluorogenic substrate for interstitial collagenase (MMP-1) and gelatinase (MMP-9). Anal Biochem. 1993;212(1):58-64.

6. Wong KF, Yuan Y, Luk JM. Tripterygium wilfordii bioactive compounds as anticancer and anti-inflammatory agents. Clin Exp Pharmacol Physiol. 2012;39(3):311-320.

7. Panthong A, Norkaew P, Kanjanapothi D, Taesotikul T, Anantachoke N, Reutrakul V. Anti-inflammatory, analgesic and antipyretic activities of the extract of gamboge from Garcinia hanburyi Hook f. J Ethnopharmacol. 2007;111(2):335-340. 


\section{Supplementary material}

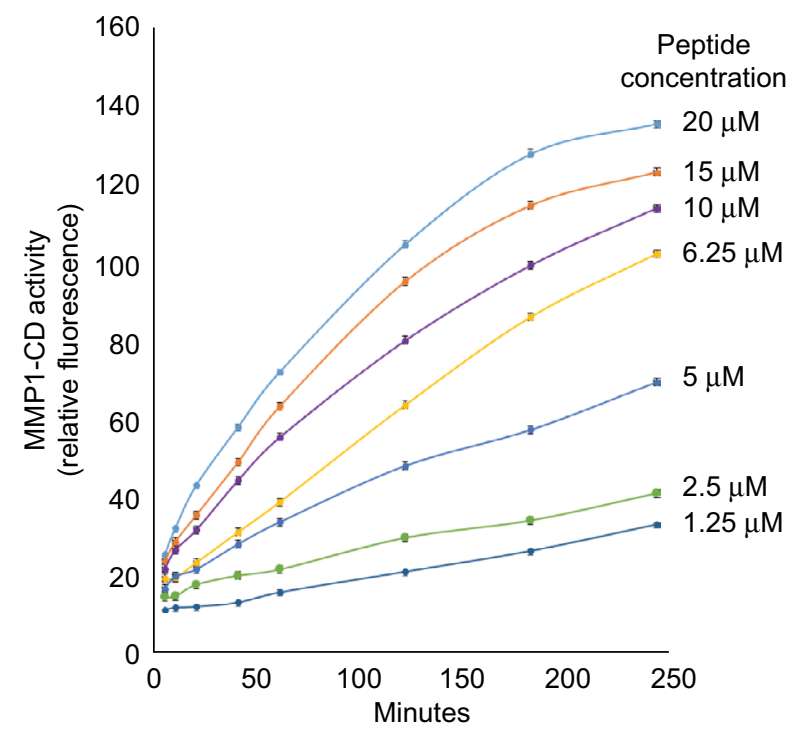

Figure SI Kinetics and peptide substrate concentration dependence of cleavage by MMPI-CD.

Notes: To optimize assay conditions for HTS, we examined both the MMPI-CD concentration dependence and the fluorogenic peptide substrate concentration dependence on the kinetics of peptide substrate cleavage by MMPI-CD. This figure shows the peptide substrate concentration dependence of cleavage by $0.2 \mathrm{ng} / \mathrm{mL}$ MMPI-CD. MMPI$C D$ was incubated with peptide substrate at the indicated concentrations for 4 hours at room temperature. Relative fluorescence intensity was monitored at the indicated times. Each point represents the mean of three independent experiments.

Abbreviations: HTS, high-throughput screening; MMPI-CD, matrix metalloproteinase-I-catalytic domain.

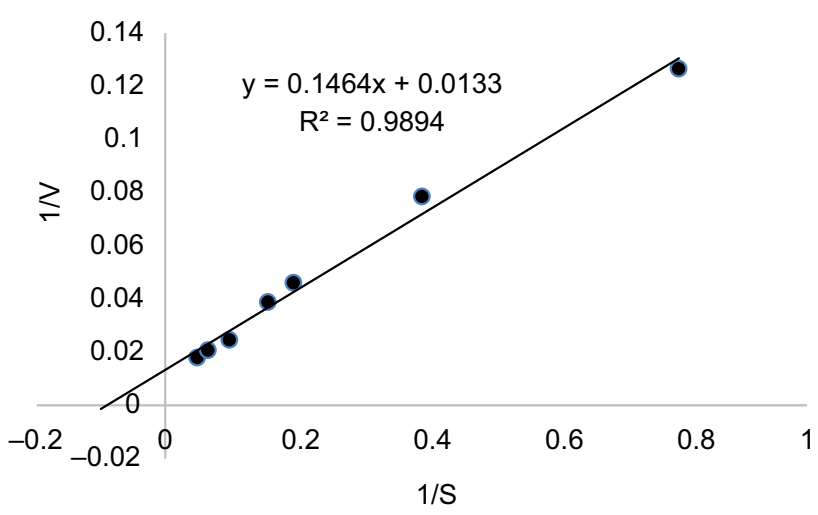

Figure S2 Determination of Km using the Lineweaver-Burk double reciprocal plot.

Notes: The $\mathrm{Km}$ was II $\mu \mathrm{m}$.

\section{Publish your work in this journal}

Clinical, Cosmetic and Investigational Dermatology is an international, peer-reviewed, open access, online journal that focuses on the latest clinical and experimental research in all aspects of skin disease and cosmetic interventions. This journal is included on PubMed. The manuscript management system is completely online and includes a very quick and fair peer-review system, which is all easy to use. Visit http://www.dovepress.com/testimonials.php to read real quotes from published authors 